The Review of Finance and Banking

print ISSN 2067-2713, online ISSN 2067-3825

Volume 11, Issue 1, Year 2019

http://dx.doi.org/10.24818/rfb.19.11.01.01, Pages 7-13

\title{
THE LIQUIDITY PREMIUM: EVIDENCE FROM THE POLISH STOCK MARKET
}

\author{
CRISTINA GANJAL
}

\begin{abstract}
The main purpose of this study is to investigate the existence of a liquidity premium on the Polish stock market, using the liquidity-adjusted CAPM. In order to measure the influence of the liquidity of stocks returns, there was constructed a liquidity factor using the newest high-low spread liquidity measure, developed by Corwin and Schultz (2012). The results have showed that there is a significant liquidity premium positively influencing the excess returns of stocks from the Poland market, and the premium is growing from the most liquid portfolio to the less liquid one.
\end{abstract}

\section{INTRODUCTION}

Liquidity wasn't always one of the first indicators that investors looked at before taking a decision, but lately, it became increasingly important to study if this factor has a significant influence on assets return. Asset pricing models investigate their risk-adjusted performance. The main question underpinning this study is whether there is a liquidity risk on the Polish capital market? If there is a liquidity risk, is it remunerated?

In order to prevent losses or to make a profit, investors want to know how quickly a given security can be traded (Chiang \& Zheng, 2015). Amihud and Mendelson (1986), one of the first researchers who investigated the role of liquidity in asset pricing, argue that the asking price, if investors want to sell their stocks, or the offered price, in case of purchasing the stocks, contains a premium for an immediate sale or an immediate buy. Therefore, the liquidity of a stock is often reflected in the bid-ask price spread. In this study I use the most recent liquidity measure developed by Corwin and Schultz (2012), which is a bid-ask spread estimator from daily high and low prices (high-low spread). The data is hard to obtain in real time because the bid-ask quotes remain available only for limited periods of time. Therefore, to calculate the high-low spread, it provides easier access to data and it is demonstrated to capture the liquidity of stocks.

The main objective of this paper is to investigate the existence of the liquidity premium on the Polish capital market using the Capital Asset Pricing Model (CAPM) adjusted to liquidity risk. In this study, the high-low spread measure proposed by Corwin and Schultz (2012) is used for the first time as the main variable for measuring liquidity and constructing a liquidity factor proven to be significant and positive in influencing the asset returns.

\section{Literature REVIEW}

The underlying question of the asset pricing models is what kinds of risk influence stock prices? The CAPM in its original version, developed by Sharpe (1964) and Linter (1965), includes just the market systematic risk. However, later was demonstrated that this model

Received by the editors April 25, 2019. Accepted by the editors June 14, 2019.

Keywords: Liquidity Premium, Liquidity Factor, Asset Pricing, Warsaw Stock Exchange.

JEL Classification: G12.

Cristina Ganja, PhD Candidate, Babeş-Bolyai University, Cluj-Napoca, Romania. E-mail: ganja.cristina@gmail.com.

This paper is in final form and no version of it will be submitted for publication elsewhere. 
has restrictive assumptions and led to a number of different approaches that have attempted to address the limitations of the model (Chen \& Sherif, 2016). For example, one of the best known models extended from CAPM are: three-factor model of Fama-French (1993) that includes not only market factor, but also the size and value factors; or Carhart model (1997) in which he demonstrated that momentum is an important risk factor which has not been priced in assets. Also, in the last decades a particular attention has been given to liquidity influence.

Most of the studies that investigate the liquidity as a variable that influence the stock return are concentrated on the US market. For instance, Amihud and Mendelson (1986) in their study, using bid-ask spread, demonstrated that the average liquidity is priced utilizing FamaMacBeth cross sectional regressions. An important finding is shown by Amihud (2002), who used his illiquidity measure to demonstrate that stocks with a lower market capitalization are more sensitive to illiquidity due to the fact that they are less attractive. The greater sensitivity of small stocks to illiquidity means that these stocks are subject to greater illiquidity risk which, if priced, should result in higher illiquidity risk premium (Amihud, 2002: 53). Also, Acharya and Pedersen (2005) studied the effect of liquidity on asset returns on the US market by constructing an liquidity-adjusted CAPM and had shown that this model performs better than the standard CAPM in terms of $R^{2}$ for cross-sectional returns and $p$-values in specification tests. Liu (2006) developed a new measure of liquidity, the standardized turnover-adjusted number of zero daily trading volumes over the prior 12 months (LM12), which showed that liquidity is an important source of price risk, obtaining a significant liquidity premium robust to the CAPM and the Fama-French three-factor model.

There are also a few studies that provide empirical evidence of existence of the liquidity premium on the european developed markets. J. L. Miralles and M. M. Miralles (2006), similar to previous studies, formed a liquidity factor using the imitation portfolios methodology, only based on the illiquidity measure of Amihud (2002). They have shown on time series data of the Spanish stock market that the best performance in explaining the assets return is given by the CAPM model that includes the liquidity factor. A more recent study of Chen and Sherif (2016) examines the relative importance of liquidity risk for the time-series and cross-section of stock returns in the UK market. To measure liquidity, the researchers formed an index composed of several liquidity measures, one of which is the high-low spread used in this study (the only time that this variable was used in an asset pricing model after it was proposed by Corwin and Schultz in 2012). According to the results of their analysis, the liquidity adjusted CAPM and Fama-French three-factor model have a statistically positive and significant liquidity premium, particularly with the portfolio of stocks with the lowest liquidity.

Evidence of the liquidity premium across the world is shown by the following studies. Liang and Wei (2012) have demonstrated that local pricing premium of liquidity is smaller in markets where the country-level corporate boards are more effective and where there are less insider trading activities. Also, the local liquidity risk is significant in 11 out of 21 developed markets, but global liquidity risk is significant in all studied markets. On the other hand, Chiang and Zheng (2015) have shown that in the most developed countries (G7), liquidity risk also has a positive and significant influence on the excess stock returns. Nevertheless, the most recent study of the liquidity premium in stock markets across 45 countries (Amihud et al., 2015), showed that the liquidity premium is bigger in emerging markets than in developed ones, witch is consistent with the first findings (Amihud \& Mendelson, 1986; Liang \& Wei, 2012; etc.).

\section{The Liquidity measure}

In this study, the liquidity measure is the high-low spread estimator developed by Corwin and Schultz (2012). Researchers have developed a bid-ask spread estimator based on daily high and low prices. The underlying assumptions of the construction of this measure are as follows (Corwin \& Schultz, 2012: 719): 
(1) Daily high prices are almost always the transactions buyer-initiated and daily low prices are almost always the transactions seller-initiated. Therefore, the ratio of high-to-low prices for one day reflects both the fundamental volatility of the stock and its bid-ask spread.

(2) The component of the high-to-low price ratio that is due to volatility increases proportionately with the length of the trading interval, while the component due to bid-ask spreads does not.

The above hypotheses imply that the sum of the price range over 2 consecutive single days reflects 2 days volatility and twice the spread, while the price range over one 2-day period reflects 2 days volatility and one spread. According to Corwin and Schultz (2012), this allows us to estimate the bid-ask spread as a function of the high-low price ratio for a single 2-day period and the high-low ratios for 2 consecutive single days.

The calculation of the high-low spread has the following steps:

$$
\beta=E\left\{\sum_{j=0}^{1}\left[\ln \left(\frac{H_{t+j}^{0}}{L_{t+j}^{0}}\right)\right]^{2}\right\}
$$

Where $H_{t+j}^{0}$ is the high observed price on the day $t+j$, and $L_{t+j}^{0}$ is the low observed price on the day $t+j$.

$$
\gamma=\left[\ln \left(\frac{H_{t, t+1}^{0}}{L_{t, t+1}^{0}}\right)\right]^{2}
$$

Where $H_{t, t+1}^{0}$ is the high price over the 2 days $(t$ and $t+1)$, and $L_{t, t+1}^{0}$ is the low price over 2 days period $(t$ and $t+1)$.

$$
a=\frac{\sqrt{2 \beta}-\sqrt{\beta}}{3-2 \sqrt{2}}-\sqrt{\frac{\gamma}{3-2 \sqrt{2}}}
$$

Further, the estimation of the high-low spread is according to the formula:

$$
S=\frac{2\left(e^{\alpha}-1\right)}{1+e^{\alpha}}
$$

To estimate the high-low spread for longer periods (e.g., monthly data), researchers recommend averaging spread estimates from all overlapping 2-day periods within the month.

\section{Data And methodology}

The sample includes 46 companies listed on the Warsaw Stock Exchange over the period January 2007 to March 2017.

Using daily data, the high-low spread was calculated based on periods of two consecutive days. After that, the monthly spread was calculated as the average of daily values (Corwin and Schultz, 2012: 748). The high-low spread may be negative, so before the monthly average of all the spread values of that month, the negative values were set to zero.

In order to compare the performance between the big and small companies, stocks were separated monthly in portfolios depending on their stock market capitalization. 


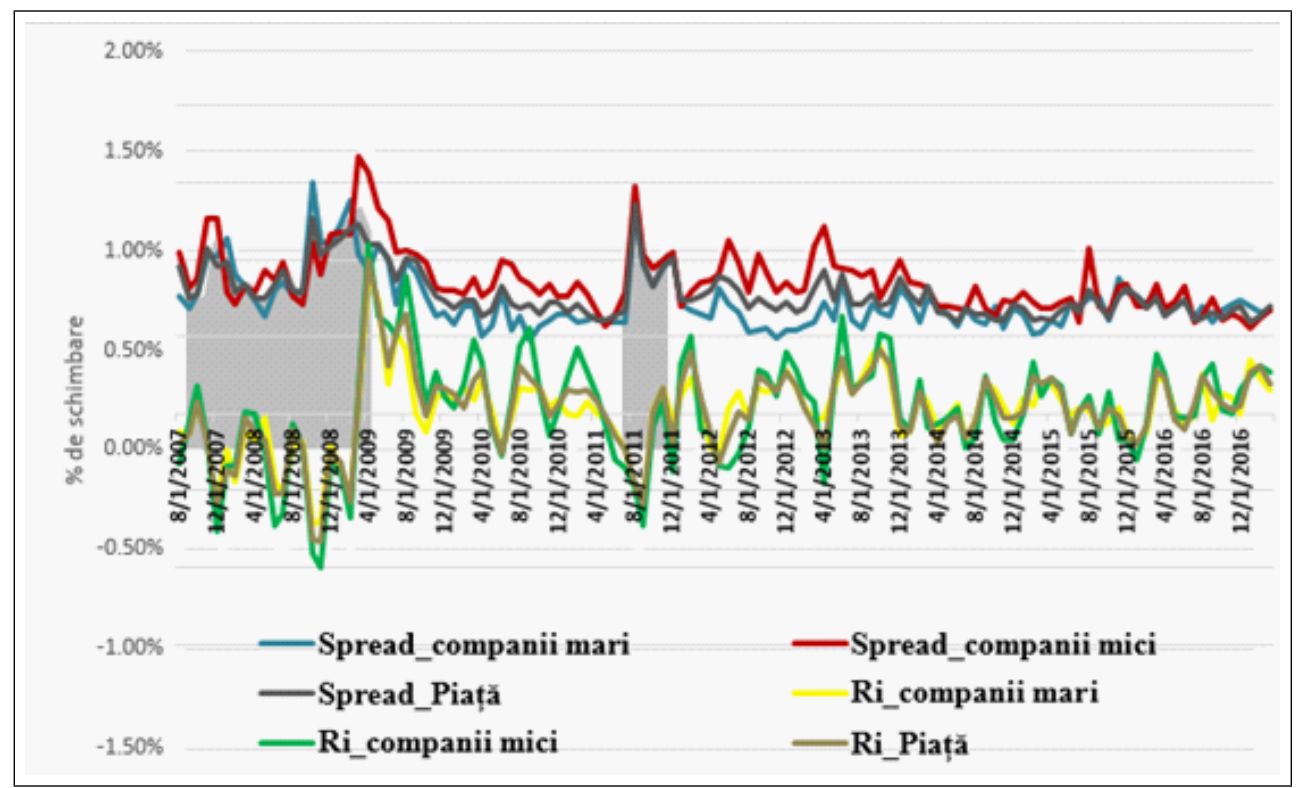

Fig. 1. The average of monthly spread and return of stocks over the period 2007-2017.

Observing the evolution in the above figure, small companies tend to have the highest spread over the entire analyzed period, and large companies have a lower spread, as well over the entire analyzed period. The results are similar to those obtained by the previous similar studies (Amihud \& Mendelson, 1986; Amihud, 2002; Liu, 2006; Corwin \& Schultz, 2012; Amihud, 2015; and others). However, during the crisis (2007-2008), there was a significant increase in the spread for all three portfolios, particularly from September 2008 to April 2009.

If the performance of the least liquid stocks exceeds the performance of the most liquid stocks, that implies the evidence of the existence of a liquidity premium (Amihud, 2002; Liu, 2006, Amihud et al., 2015). Thus, the stocks were divided into portfolios based on the liquidity measure and their performance. Monthly, stocks are sorted into portfolios based on their liquidity: Pf_HL contains the first 13 companies with the lowest spread (highest liquidity); Pf_2 contains the next 10 companies with high liquidity; Pf_LL contains the first 13 companies with the highest spread (lowest liquidity) and the Pf_3 contains the next 10 companies with low liquidity. The constructed Portfolios are equally weighted with all the stocks in their composition.

\begin{tabular}{|c|c|c|c|c|c|}
\hline \multicolumn{6}{|c|}{ Table 1: Performance of portfolios classified by liquidity } \\
\hline & Pf_HL & Pf_2 & Pf_3 & Pf_LL & LL-HL \\
\hline Performance: & & & & & \\
\hline HP1m & $0.0257 \%$ & $0.0308 \%$ & $0.0339 \%$ & $0.0521 \%$ & $0.0265 \%$ \\
\hline HP6m & $0.0248 \%$ & $0.0240 \%$ & $0.0121 \%$ & $0.0424 \%$ & $0.0175 \%$ \\
\hline Characteristics: & & & & & \\
\hline MV & 7321.73 & 7222.98 & 7113.46 & 4816.10 & -2505.64 \\
\hline HL Spread & $0.4508 \%$ & $0.6593 \%$ & $0.8084 \%$ & $1.1709 \%$ & $0.7201 \%$ \\
\hline
\end{tabular}

The table presents the average returns of portfolios classified by liquidity and held for a certain time, along with the market value (MV) and high-low spread. The column names Pf_HL, Pf_2, Pf_3 and Pf_LL are the portfolios, and the column LL-HL is the difference between the least liquid and the most liquid portfolio. HP1m and HP6m are the average monthly portfolio returns from January 2007 to March 2017, with a holding period of each portfolio of one month (HP1m) and of 6 months (HP6m) respectively.

According to the fact that there is a difference between the returns of the least liquid portfolio and the most liquid portfolio, it shows us that there is a liquidity premium, but is it significant or not?

Further, I investigated the performance of portfolios sorted by liquidity, using the CAPM. 


$$
R_{i t}-R_{f t}=\alpha_{i}+\beta_{i}\left(R_{m t}-R_{f t}\right)+\varepsilon_{i t}
$$

Where $R_{i t}$ is the return of portfolio $i$ in month $t, R_{f t}$ is the one-month Poland T-bill rate for month $t$ and $R_{m t}$ is the return of market portfolio (WIG20) in month $t$.

\begin{tabular}{|l|l|l|l|l|l|}
\hline \multicolumn{6}{|c|}{ Table 2: CAPM performances of portfolios classified by liquidit } \\
\hline & $\mathbf{P f} \mathbf{P f}_{\mathbf{H}} \mathbf{2}$ & $\mathbf{P}$ & $\mathbf{P f} \mathbf{3}$ & $\mathbf{P f} \mathbf{\text { LL }}$ & LL-HL \\
\hline$\widehat{\boldsymbol{\alpha}}$ (t-statistic) & -0.003528 & -0.003453 & -0.003435 & -0.003205 & -0.003626 \\
\hline & $(-15.75)$ & $(-14.62)$ & $(-14.18)$ & $(-11.07)$ & $(-20.36)$ \\
\hline$\widehat{\boldsymbol{\beta}}$ (t-statistic) & 0.02543 & 0.02900 & 0.02696 & 0.03423 & 0.009418 \\
\hline & $(6.988)$ & $(7.55)$ & $(6.84)$ & $(7.27)$ & $(3.25)$ \\
\hline$R^{\mathbf{2}}$ & 0.2875 & 0.3206 & 0.2794 & 0.3045 & 0.0805 \\
\hline
\end{tabular}

The table presents the estimated $\widehat{\boldsymbol{\alpha}}$ and $\widehat{\boldsymbol{\beta}}$ of the CAPM, and the $R^{2}$ of the model.

According to Corwin and Schultz (2012), if there is a liquidity premium, then $\widehat{\boldsymbol{\alpha}}$ should be significant and grow from the most liquid portfolio to the least liquid. In this case, as is shown in Table 2, the estimated alpha is significant and indeed has an increasing evolution from left to right, but it is negative, which shows an abnormal negative return.

Estimating market risk from daily data presents serious econometric biases. In order to correct this error, beta parameter was adjusted by the method of Scholes and Williams (1977).

\begin{tabular}{|c|c|c|c|c|c|}
\hline & Pf_HL & Pf_2 & Pf_3 & Pf_LL & LL-HL \\
\hline$\widehat{\boldsymbol{\beta}}$ & 0.049148 & 0.054475 & 0.05404 & $0.0 \overline{6} 7172$ & 0.018024 \\
\hline
\end{tabular}

From the above table we see that market risk increases from left to right. The least liquid companies that tend to be the smallest and achieve higher returns have a higher market risk than the more liquid companies that tend to be the largest and least profitable.

In this study, similar to previous studies (Amihud, 2002; Liu, 2006; Miralles \& Miralles, 2006; etc), the liquidity premium is investigated by introducing a liquidity factor, built on the liquidity measure (the high-low spread in our case), into the CAPM. The liquidity factor (LF) construction is similar to the SMB and HML of Fama-French (1993) factors or LIQ factor of Liu (2006), using the method of mimicking portfolios. Therefore, the liquidity factor is constructed as the monthly profits from buying one unit of equally weighted less liquid portfolio (Pf_LL) held for 1 month after portfolio formation, and selling one unit of equally weighted most liquid portfolio (Pf_HL) held for 1 month (LF1m), and similar for portofolios held for 6 months (LF6m).

\begin{tabular}{|l|l|l|}
\hline \multicolumn{3}{|c|}{ Table 4: Descriptive statistics of the liquidity factors } \\
\hline & LF1m & LF6m \\
\hline Media (\%) & $\mathbf{0 . 0 2 6 5}$ & $\mathbf{0 . 0 1 7 5}$ \\
\hline Mediana (\%) & $\mathbf{0 . 0 1 5 8}$ & $\mathbf{0 . 0 2 2 1}$ \\
\hline Min (\%) & $\mathbf{- 0 . 2 6 5}$ & $\mathbf{- 0 . 4 1 9}$ \\
\hline Max (\%) & $\mathbf{0 . 4 8 4 4}$ & $\mathbf{0 . 2 4 2 7}$ \\
\hline
\end{tabular}

Finally, we test the significance of the liquidity premium on the Warsaw Stock Exchange:

$$
R_{i t}-R_{f t}=\alpha_{i}+\beta_{m, i}\left(R_{m t}-R_{f t}\right)+\beta_{l, i} F L+\beta_{D, i} D c+\varepsilon_{t}
$$

Where $R_{i t}-R_{f t}$ is the excess return of the portfolio $i, R_{m t}-R_{f t}$ is the excess return of the market portfolio, $F L$ is the liquidity factor and $D c$ is the dummy variable that has value 1 in the crisis period and value 0 in the rest of the analyzed period. 


\begin{tabular}{|c|c|c|c|c|}
\hline \multicolumn{5}{|c|}{ Table 5: Performance of the liquidity adjusted CAPM } \\
\hline & Pf HL & Pf_2 & Pf 3 & Pf_LL \\
\hline \multicolumn{5}{|c|}{ A: Liquidity Adjusted CAPM with FL1m } \\
\hline \multirow[t]{2}{*}{$\widehat{\alpha}$} & $-0.002335^{* * *}$ & $-0.002344^{* * *}$ & $-0.002373^{* * *}$ & $-0.002335^{* * *}$ \\
\hline & $(-8.40)$ & $(-9.10)$ & $(-8.73)$ & $(-8.40)$ \\
\hline \multirow[t]{2}{*}{$\widehat{\boldsymbol{\beta}}_{\mathrm{m}}$} & $0.02013^{* * *}$ & $0.02276^{* * *}$ & $0.01848^{* * *}$ & $0.02013^{* * *}$ \\
\hline & $(3.65)$ & $(3.69)$ & $(4.18)$ & $(3.65)$ \\
\hline \multirow[t]{2}{*}{$\widehat{\beta}_{1}$} & 0.1825 & $0.3353^{* * *}$ & $0.5565 * * *$ & $1.1825^{* * *}$ \\
\hline & $(1.93)$ & $(-3.78)$ & $(5.73)$ & $(12.52)$ \\
\hline \multirow[t]{2}{*}{$\widehat{\boldsymbol{\beta}}_{\mathrm{D}_{\mathrm{c}}}$} & $-0.004^{* *}$ & $-0.0038^{* * *}$ & $-0.004^{* * *}$ & $-0.004^{* *}$ \\
\hline & $(-4.65)$ & $(-3.78)$ & $(-4.98)$ & $(-4.65)$ \\
\hline \multirow[t]{2}{*}{$\mathbf{R}^{2}$} & 0.5541 & 0.5614 & 0.5823 & 0.7436 \\
\hline & B: Liq & ty Adjusted & $P M$ with $F L$ & \\
\hline \multirow[t]{2}{*}{$\widehat{\alpha}$} & $-0.0022^{* * *}$ & $-0.0022 * * *$ & $-0.0021^{* * *}$ & $-0.0019 * * *$ \\
\hline & $(-8.09)$ & $(-8.56)$ & $(-7.30)$ & $(-5.57)$ \\
\hline \multirow[t]{2}{*}{$\widehat{\boldsymbol{\beta}}_{\mathrm{m}}$} & $0.0213^{* * *}$ & $0.0252^{* * *}$ & $0.0220^{* * *}$ & $0.0269 * * *$ \\
\hline & $(3.97)$ & $(4.06)$ & $(4.76)$ & $(4.36)$ \\
\hline \multirow[t]{2}{*}{$\widehat{\beta}_{1}$} & 0.074 & 0.054 & 0.264 & $0.765^{* * *}$ \\
\hline & $(0.42)$ & $(0.24)$ & $(1.23)$ & $(2.95)$ \\
\hline \multirow[t]{2}{*}{$\widehat{\boldsymbol{\beta}}_{\mathrm{D}_{\mathrm{c}}}$} & $-0.0041^{* * *}$ & $-0.004^{* * *}$ & $-0.0043^{* * *}$ & $-0.0049 * * *$ \\
\hline & $(-4.65)$ & $(-3.79)$ & $(-5.07)$ & $(-4.76)$ \\
\hline $\mathbf{R}^{2}$ & 0.54 & 0.53 & 0.50 & 0.50 \\
\hline
\end{tabular}

In this table are presented the estimates of the regression 4.2 described above. In section A are presented the estimates of the liquidity adjusted CAPM and their significance, using the liquidity factor constructed based on 1 month holding period; and in section B, using the liquidity factor constructed based on 6 months holding period.

The results are showing that liquidity measured by high-low spread has significant and positive influence in explaining the excessive assets return of all portfolios for 1 month holding period. At the same time, the portfolio liquidity risk increases from 0.1825 for the most liquid portfolio (Pf_HL) to 1.1825 for the least liquid portfolio (Pf_LL).

As regarding the liquidity factor built on a 6 -month holding period, according to Table 5 , the liquidity premium is relatively small and has an insignificant influence in the first three portfolios in the ascending order of liquidity, yet it is significant for the least liquid portfolio, with a liquidity risk of 0.765 . This results are consistent with the previous studies that had shown that the most illiquid stocks are more sensitive to liquidity risk (Amihud, 2002; Liang \& Wei, 2012; and other studies).

\section{Conclusion}

Based on the Polish market survey, the results are showing normal characteristics of the companies grouped according to their liquidity. The least liquid companies are also those with a lower stock market capitalization, have a higher transaction cost (higher high-low spread), higher liquidity risk and they outperfom the returns of more liquid companies. At the same time, the more liquid companies are the largest, with a lower trading cost and a lower liquidity risk.

The liquidity premium is shown to be significant and positive for all portfolios if they are held for a short term period ( 1 month). For a relatively medium holding period (6 months), the liquidity premium is significant only for the least liquid portfolio.

The results show that liquidity is priced in the Polish market, especially for holding stocks for a short period of time. The liquidity premium is significant according to the liquidity adjusted CAPM, and has a positive influence on the excess returns of the securities. The results are consistent with those obtained in the previous studies, both on the European markets (Mirales 
\& Mirales, 2006; Chen \& Sherif, 2016) and on the US markets (Amihud, 2002; Liu, 2006, and other studies).

\section{REFERENCES}

[1] Acharya, V., Pedersen, L. (2005). Asset pricing with liquidity risk, Journal of Financial Economics, vol. 77, no. 2, 375-410.

[2] Ali, S., Liu, B., Su, J.J. (2017). Corporate governance and stock liquidity dimensions: Panel evidence from pure order-driven Australian market, International Review of Economics and Finance, 50, 275-304.

[3] Amihud, Y., \& Mendelson, H. (1986). Asset pricing and the bid-ask spread. Journal of Financial Economics, $17(2), 223-249$.

[4] Amihud, Y. (2002). Illiquidity and stock returns: Cross-section and time-series effects, Journal of Financial Markets, 5 (1), 31-56.

[5] Amihud, Y., Hammed, A., Kang, W., Zhang, H. (2015). The illiquidity premium: International evidence, Journal of Financial Econometrics, 117, 350-368.

[6] Asparouhove, E., Bessembinder, H., Kalcheva, I. (2010). Liquidity biases în asset pricing tests, Journal of Financial Economics, 96, 215-237.

[7] Assefa, T. A., Mollick, A. V., (2014). African stock market returns and liquidity premia, Journal of International Financial Markets, Institutions \& Money, 32, 325-342.

[8] Breeden, D., (1979). An intertemporal asset pricing model with stochastic consumption and investment opportunities. Journal of Financial Economics, 7, 265-296.

[9] Brennan, M. J., Wang, A. W. (2010). The mispricing return premium, The Review of Financial Studies, vol. 23, no. 9, 3437-3468.

[10] Carhart, M. M. (1997). On persistence in mutual fund performance. Journal of Finance, 52 (1), 57-82.

[11] Chen, J., Sherif, M., (2016). Illiquidity premium and expected stock returns in the UK: A new approach, Physica A, 458, 52-66.

[12] Corwin, S. A., Schultz, P. (2012). A simple way to estimate bid-ask spread from daily high and low prices, The Journal af Finance, vol. LXVII, no. 2, 719-759.

[13] French, K. R., Roll, R. (1986). Stock return variances: The arrival of information and the reaction of traders, Journal of Financial Economics, vol. 17, no. 1, 5-26.

[14] Goyenko, R. Y., Holden, C. W., Trzcinka, C. A. (2009). Do liquidity measures measure liquidity? Journal of financial Economics. 92 (2), 153-181.

[15] Janssen, J., Manca, O., Manca, R., (2013), Applied Diffusion Processes from Engineering to Finance, John Wiley \& Sonc, Inc., Hoboken, NJ (USA).

[16] Liang, S. X., Wei, J. K. C., (2012). Liquidity risk and stock returns around the world, Journal of Banking \& Finance, vol. 36 , no. 12, 3274-3288.

[17] Lin, J., Singh, A. K., Sun, P., Yu, W. (2012). Price delay and liquidity risk, Journal of Financial Markets, $17,150-173$.

[18] Liu, W. (2006). A liquidity-augmented capital asset pricing model, Journal of Financial Economics, 82, 631-671.

[19] Miralles, J. L., Miralles, M. M., (2006). The role of an illiquidity risk factor in asset pricing: Empirical evidence from the Spanish stock market, The Quarterly Review of Economics and Finance, 46, 254-267.

[20] Lazăr, D. (2011). Econometrie financiară, Casa Cărţii de Ştiinţă, Cluj - Napoca.

[21] Todea, A. (2008). Investiţii, Casa Cărţii de Ştiinţă, Cluj - Napoca. 